\title{
Wittgenstein sobre el fingimiento y las otras mentes
}

\author{
Mario Gensollen \\ Departamento de Filosofía \\ Universidad Autónoma de Aguascalientes \\ mgenso@correo.uaa.mx
}

La posibilidad de fingir parece engendrar una dificultad. Pues parece reducir el valor de la evidencia externa, esto es: anular la evidencia.

Se dirá: O tiene dolor o tiene una vivencia del fingir. Todo lo externo puede expresar esto y aquello (LSPP II, 42) ${ }^{1}$.

\section{El fingimiento como problema filosófico}

El problema del fingimiento podría considerarse, desde un punto de vista filosófico, como secundario. Puede incluso cuestionarse su interés. En otros casos, también puede tomarse por una simple instancia de otros problemas filosóficos de primer orden. Si optamos por esta tercera posibilidad, habría que mencionar de qué problema o problemas de primer orden es una instancia. De este modo, surgirían otras posibilidades.

\footnotetext{
${ }^{1}$ En la bibliografía señalo las formas abreviadas de citar la obra de Wittgenstein.
} 
En un primer momento, podríamos apelar al problema de las otras mentes, dentro del cual la posibilidad misma de que otro finja se muestra como un desafío a nuestro uso correcto o significativo del lenguaje mental en tercera persona, como de nuestro conocimiento de las otras mentes. Desde esta perspectiva, el problema mismo sería una instancia particular de algunos problemas epistémicos de primer orden (algunos ligados a desafíos escépticos). Otra posibilidad epistémica consiste en que el fingimiento se muestra como un desafío al testimonio como fuente justificada de nuestras creencias, y por ello también cuestiona algunas de nuestras prácticas —algunas de ellas básicas- que implican la confianza. Una última opción presenta la posibilidad del fingimiento como una forma de justificación de la ya clásica dicotomía real/ aparente, y hace de ella una instancia (entre muchas otras) de problemas metafísicos u ontológicos clásicos. Lo cierto es que pocas veces se ha tratado, y cuando lo ha sido, el debate fue escaso.

Hace un par de décadas, algunos filósofos trataron de revivir el debate en torno al fingir para aclarar algunos puntos acerca de lo ficticio y la ficción (ver, e.g., Currie 1985; 1997). Pero dicha discusión puede ser considerada aún prematura. Para un debate más reciente, el problema del fingir empieza a ser central para aclarar el papel de la imaginación y lo imaginario, $y$, por tanto, como un tema que es necesario abordar, al menos de modo indirecto, para clarificar actividades tales como los experimentos mentales, el juicio modal y el razonamiento contrafáctico (ver Nichols 2006). De cualquier forma, la literatura filosófica aún sigue siendo escasa.

Recientemente, ha sido la ciencia cognitiva la que ha prestado atención al fingir. Aunque su atención se ha centrado de manera focal en un tipo muy específico de fingimiento: 
el que implican los juegos infantiles. A partir de dicho paradigma, algunos han intentado trazar un mapa de los mecanismos cognitivos que subyacen a los juegos de fingimiento. Por ello, ahora disponemos de una gran cantidad de trabajos tanto conceptuales como empíricos sobre el fingir (ver, e.g., Currie 1995, 1997; Gordon \& Barker 1994; Harris 1991, 1994, 1995; Harris \& Kavanaugh 1993, 1994; Leslie 1987; Lilliard 1993). Incluso, disponemos de teorías que tratan de ser exhaustivas en torno a los mecanismos cognitivos que subyacen al fingimiento (ver Nichols \& Stich 2000).

Otra arista que ha detonado cierto interés y debate sobre el fingimiento ha sido la de los estudios sobre la capacidad de descifrar o leer otras mentes (el denominado mindreading). El debate, polarizado entre los defensores de la teoría de la simulación (simulation theory), y los de la teoría de la teoría (theory theory), parte de que existe una conexión importante entre los juegos de fingimiento y el mindreading. Aunque los defensores de ambos bandos aceptan esta conexión, existe una acalorada disputa acerca de los mecanismos mentales que hacen posible el mindreading, y en este punto el fingir desempeña un papel central en el debate.

Independientemente del bando por el que se tome partido, tanto los defensores de la teoría de la simulación como los defensores de la teoría de la teoría aceptan que el fingir desempeña un papel central en una gran variedad de importantes capacidades cognitivas, tales como el razonamiento contrafáctico, la planificación condicional, la empatía, la comprensión moral, la apreciación literaria y la imaginería visual (visual imagery). De cualquier manera, los participantes en el debate cognitivista sobre el fingir admiten que es necesario, como un primer paso indispensable, desarrollar una teoría plausible de los mecanismos mentales que subyacen a la capacidad de fingir como tal. 
Desde una perspectiva wittgensteiniana, pienso antes de una teoría cognitivista del fingir (la cual puede ser útil e, incluso, en un segundo momento, indispensable), es necesaria una gramática del fingir: es necesario poner en claro el mapa conceptual que gira en torno al fingimiento; aclarar, por tanto, las prácticas en las que desempeña un papel, y qué papel desempeña en ellas (con qué diversidad de propósitos fingimos), cómo es que el fingir forma parte de nuestra historia natural, y cómo éste moldea nuestra forma de vida. Sin dicha gramática no es imposible que los desarrollos cognitivos caigan en algunos errores que son posibles de evitar.

A partir de estas primeras coordenadas, resulta aún más arriesgado ligar el problema del fingimiento al nombre y a la obra de Wittgenstein. Un breve repaso por la bibliografía secundaria en torno a su pensamiento nos arroja, sorpresivamente, resultados casi nulos. El tema no ha sido tratado directamente desde una perspectiva wittgensteiniana. Las razones podrían ser varias. La primera, y más evidente, es que no es hasta los cuadernos de 1949, 1950 y 1951 (los MS 169; $170 ; 171 ; 173$; 174; 176) cuando Wittgenstein, casi de manera obsesiva, repara en la gramática del fingir². Dichos cuadernos no fueron publicados hasta 1992 en inglés (con el título Last Writings on the Philosophy of Psychology, Volume II, The Inner and the Outer), y sólo se publicaron de manera fragmentaria. En castellano, la primera edición, basada en la edición inglesa, data de 1996. Sólo es a partir del año 2000 que disponemos de los cuadernos íntegros, con la edición electrónica del Nachlass a cargo de la Universidad de Bergen. Aunado a esto,

\footnotetext{
${ }^{2}$ Con esto no quiero decir que el problema no haya sido visualizado por Wittgenstein desde las Investigaciones. En ellas, ya repara Wittgenstein en algunas aristas de la gramática del fingir, pero no está lo suficientemente desarrollada como lo está en los escritos de los años posteriores. Ver, e.g., $P U$ II 165-195; 111-367.
} 
si tomamos en cuenta que los estudios canónicos sobre los escritos de filosofía de la psicología de Wittgenstein fueron publicados antes o muy poco después de la aparición de los mencionados cuadernos (ver, e.g., Schulte 1987; Bouveresse 1976; Hacker 1993a, 1993b), podríamos darnos una idea del porqué el problema del fingir no figura comúnmente como un tópico wittgensteiniano en la literatura crítica.

Otra razón, mucho menos histórica y más exegética, tiene que ver con ciertas interpretaciones sobre algunos puntos clave de las Investigaciones filosóficas. En particular, aquellos sobre el problema del seguir reglas, y el tan atractivo argumento contra el lenguaje privado. Detrás de las muy disímiles interpretaciones que se han ofrecido de estos puntos desde la publicación de las Investigaciones, se encuentra un desacuerdo en torno a la forma de comprender ciertos conceptos como «privacidad», «interioridad», «forma de vida», «historia natural», «criterio», «gramática», «práctica», etc. No queda muy claro - en ocasiones- cuál es el punto de Wittgenstein en sus argumentos contra el lenguaje privado. A propósito de ello, Stanley Cavell ha lanzado la pregunta al aire: «¿en qué espíritu es en el que Wittgenstein «niega» la «posibilidad» de un lenguaje privado?» (1979; 84). Cavell, mucho más adelante, es aún más explícito:

«¿Qué es lo que nos causa la impresión de que Wittgenstein desea negar que el alma es privada? ¿Qué es lo que nosotros deseamos rechazar, contra las enseñanzas wittgensteinianas, cuando nos vemos obligados a proteger la privacidad del alma contra él? ¿Es porque creemos que la afirmación de la privacidad es la afirmación de la existencia del alma misma? ¿Cuál es la idea que tenemos de la privacidad?» (1979; 329). 
No son pocas las formas de leer a Wittgenstein que no nos dan una respuesta satisfactoria a las preguntas cavellianas. Muchas de ellas incluso las ignoran. A fin de cuentas, el problema de la privacidad no pocas veces está subordinado a otros problemas que algunos pueden considerar más interesantes o importantes (generalmente, ligados a la filosofía de las matemáticas).

Partiré de un supuesto contrario al habitual, el cual espero que al final haga ver su posible pertinencia. Es, precisamente, el mismo supuesto del que parte Cavell para leer las Investigaciones, y con el que pienso que es posible leer el pensamiento del segundo Wittgenstein: «la relación correcta entre lo interno y lo externo, entre el alma y su sociedad, constituye el tema de las Investigaciones en su conjunto. Este tema, podría decir, es lo que proporciona el sentido moral del libro» (1979; 329). En otras palabras, el énfasis excesivo que hace Wittgenstein tanto en el carácter público del lenguaje, como en la exterioridad de los criterios, está al servicio de una corrección de nuestro mapa conceptual sobre lo interno y lo externo. En este contexto, la gramática del fingir que Wittgenstein desarrolló los últimos años de su vida es la última fase del ciclo argumental que inició en las Investigaciones con sus argumentos contra el lenguaje privado (aunque esta última idea no es de Cavell, quién incluso parece desecharla $\left.{ }^{3}\right)$.

Establecido un somero mapa del terreno, partamos ya de la primera posibilidad: interpretar el problema del fingimiento como una instancia particular del problema de las

\footnotetext{
${ }^{3}$ Así lo justifica Cavell: «No one will insist that privacy and secrecy have nothing to do with one another; that is, no one will deny that a sense of secrecy captures, or enforces, a particular sense of privacy. But that sense of privacy ought, on its face, to seem of limited metaphysical interest, while possibly of pervasive political significance» $(1979 ; 330)$.
} 
otras mentes. Para caracterizar inicialmente este problema, tendríamos que preguntarnos de qué tipo de justificación disponemos para atribuir significativamente predicados psicológicos a otros. Otra forma, mucho más general, consistiría en plantear un desafío acerca de la posibilidad misma de hablar de la vida mental, así como de la forma en la que podríamos hablar de la misma.

De ordinario no surgen dificultades ni confusiones acerca de los predicados psicológicos que yo mismo me atribuyo, ni de si éstos coinciden con atribuciones que otros hacen de sí mismos (aunque, claro, no en pocas ocasiones surgen anomalías en la comunicación). Cuando $A$ dice «Me duele la muela», $B$ no suele cuestionar (a menos que se presente una anomalía, la cual siempre es posible señalar) si dicha atribución coincide con la que él ha hecho o podría hacer de sí mismo (cuando $B$ dice «Me duele la muela»). La pregunta filosófica, a partir de estas consideraciones, sería la siguiente: ¿en qué se fundamenta el acuerdo entre las personas cuando hablan de su vida mental? Una forma, aún más general, sería la siguiente: ¿cuál es la condición de posibilidad de la comunicación?

La respuesta de Wittgenstein a esta pregunta es sobria: ««¿Dices, pues, que la concordancia de los hombres decide lo que es verdadero y lo que es falso?» - Verdadero y falso es lo que los hombres dicen; y los hombres concuerdan en el lenguaje. Ésta no es una concordancia de opiniones, sino de forma de vida (Lebensform)» (PU 241). Lo que Wittgenstein quiere decir es que el uso del lenguaje mental (y no sólo de éste) está sustentado principalmente en las normas, prácticas, hábitos e instituciones a las que pertenecen los hablantes competentes de una lengua, y que constituyen su forma de vida. 
El desafío escéptico - uno de tantos, y una forma entre muchas- a veces ha tomado una forma similar a la que sigue: ¿bajo qué criterios podemos afirmar que el uso que haces de tus conceptos para referirte a la vida mental de otros es correcto? Sólo habría que ampliar un poco la respuesta anterior: dado que todos los hablantes competentes de una lengua formamos nuestras capacidades lingüísticas y extralingüísticas en un contexto común y compartido, dicho contexto es la pauta de corrección de nuestros usos conceptuales. Éste es, al menos, el primer paso para disolver el problema del escepticismo de las otras mentes.

Atengámonos a una forma concreta del desafío escéptico general, a saber: ¿de qué tipo de justificación dispongo para emplear términos mentales en tercera persona? Una manera técnica de plantear el mismo desafío sería la siguiente: ¿cómo justificamos las alioatribuciones de predicados psicológicos? Para contextualizar el desafío escéptico sobre el empleo del lenguaje mental en tercera persona, habría que recordar la lectura escéptica de Kripke (1982) (aunque se sabe que la lectura que hace Kripke es mucho más profunda, así como su desafío, ya que lo que está en cuestión no sólo es el uso del lenguaje mental en tercera persona, sino el uso significativo del lenguaje mismo).

El desafío escéptico que lanza Kripke es suficientemente general: dado que, pareciera que el uso de nuestros conceptos no está determinado, cualquier empleo de un concepto en tiempo presente constituye una hipótesis sobre la corrección de su uso. En otras palabras, $A$ parece no disponer de ningún tipo de justificación al emplear en presente el concepto «dolor de muelas», dado que el significado de tal concepto no está determinado por ninguno de sus usos pasados. En este punto, el desafío kripkeano no sólo ataca mis usos de 
lenguaje mental en tercera persona, sino también en primera persona. Pero la implicación es obvia: tampoco el uso que hace $A$ del concepto «dolor de muelas» estaría determinado por las vidas mentales de otras personas, pues dichas vidas constituyen un misterio para $A$.

Como vimos, algunas (no pocas) críticas a Kripke han tratado de mostrar que el desafío que plantea con respecto a nuestras aplicaciones de conceptos (por tanto, al uso significativo del lenguaje) no es un desafío real. De ello implican que el problema de las otras mentes, al ser una instancia particular del desafío general, quedaría a su vez desarticulado. Cierto es que la lectura kripkeana del parágrafo 201 de las Investigaciones quizá sea una malinterpretación, resultado de una incomprensión de la naturaleza de nuestros acuerdos y su fundamento (donde conceptos como «criterio», «historia natural»y «forma de vida» juegan un rol protagónico).

Sin embargo, el problema no es tan sencillo. En primer lugar, si se argumenta de esta forma, podría aceptarse de manera implícita la clave exegética principal de Kripke: a saber, que el argumento contra el lenguaje privado es una instancia particular del problema de la indeterminación de la regla. No obstante, el problema de la indeterminación de la regla, y la desarticulación que Wittgenstein realiza de éste, pueden leerse sólo como la primera fase del ciclo argumental, el cual es completado en parte por el argumento contra el lenguaje privado.

De este modo —alguno podría pensar-, dado que el problema de la indeterminación de la regla no es un problema real, y por tanto no es posible cuestionar, a partir de la aparente indeterminación de la regla, de manera global nuestro uso significativo del lenguaje, y en particular nuestro uso del lenguaje mental tanto en primera como en tercera 
persona, todo queda en manos de la posible conclusividad del argumento contra el lenguaje privado. Entonces, si la conclusión del argumento es verdadera (a saber: dado que no tiene sentido referirnos a objetos privados en un lenguaje público, y no podemos referirnos a ellos en un lenguaje privado, por tanto, no podemos referirnos a ellos), la gramática de lo interno y lo externo quedaría corregida, y la privacidad no sería más una amenaza a nuestras pretensiones de conocimiento de la vida mental de otros. Los que así razonan, vieron en los cuadernos de 1949-51 una mera repetición, con ejemplos distintos, de lo que Wittgenstein ya había dicho en las Investigaciones. La gramática del fingir sería, así, innecesaria desde el punto de vista del argumento central, aunque quizá (en el mejor de los casos) una colección de notas un tanto folclóricas, con interés histórico y anecdótico. Sin embargo, tal razonamiento quizá no sea del todo acertado.

Lo que habría que indicar es que el razonamiento anterior queda incompleto. Pues es en este punto donde la gramática del fingir adquiere su sitio en el ciclo argumental. Ya que Wittgenstein ha negado que el desafío escéptico de la indeterminación de la regla sea un problema real, y ha argumentado contra la posibilidad misma de un lenguaje privado (haciendo uso, para ello — entre otras herramientas argumentativas-, del caso del lenguaje de las sensaciones), parecería que la privacidad deja de ser una amenaza epistémica, y la concepción cartesiana de la mente queda desacreditada. A pesar de ello, y por decirlo de alguna manera, Wittgenstein sólo ha argumentado contra la privacidad fuera de cualquier posible juego del lenguaje: él nos muestra que la privacidad no es una amenaza en abstracto, y cuando alguien nos desafía apelando a su posibilidad, lo único que habría que mostrarle es que lo que dice parece carecer de sentido. Sin embargo, 
Wittgenstein se percata de manera acertada de que existen juegos del lenguaje que reintroducen la privacidad como amenaza, y que vuelven a trastocar la gramática misma de lo interno y lo externo. El juego del lenguaje del fingimiento es paradigmático a este respecto.

De esta posibilidad es de la que no se percata Cavell, pues niega interés filosófico a uno de los sentidos ordinarios más relevantes del término «privacidad»: «el secreto» (secrecy). Cuando Wittgenstein señala en el parágrafo 246 de la primera parte de las Investigaciones: «De mí no puede decirse en absoluto (excepto quizá en broma) que sé que tengo dolor. ¿Pues qué querrá decir esto, excepto quizá que tengo dolor?», Cavell cree que el punto de Wittgenstein no es negar que sólo yo pueda expresar mis dolores, y que pueda hacerlo independientemente de lo que suceda en o con otra persona. A partir de esto, Cavell critica a quienes creen que el punto de Wittgenstein es negar la privacidad del alma como si fuese una cuestión de secreto. De lo que — cree Cavell— se seguiría simplemente que «no tenemos secretos impublicables» (we have no unutterable secrets), y por tanto no habría algo así como una «privacidad inquebrantable» (unbridgeable privacy).

Cavell acierta en que si interpretamos que Wittgenstein niega en el argumento contra el lenguaje privado la privacidad como una cuestión de secreto, «la idea filosófica o metafísica de privacidad no se captura, o se hace irreconocible» $(1979 ; 330)$. Por tanto, Cavell niega que la idea misma de «secreto» pueda tener algún interés filosófico. Esto es correcto, pero sólo si consideramos que está cuestionando la relevancia de un sentido metafísico de «secreto». Pero también disponemos de un sentido ordinario de «secreto», muy usado y penetrante, que no es metafísico, sino epistémico. 
Contra esta interpretación, podríamos pensar que de la negación de la privacidad metafísica no se sigue necesariamente la negación de la privacidad epistémica (al menos no aquella que tiene un papel en ciertos juegos del lenguaje: paradigmáticamente en el fingimiento). Nosotros podemos aceptar la conclusión del argumento contra el lenguaje privado y, a pesar de ello, no disponer de todas las herramientas para combatir otra variante del escepticismo de otras mentes.

La amenaza escéptica en este punto - ya que hemos planteado al fingimiento como una posibilidad epistémica que desafía nuestro uso del lenguaje mental en tercera persona, y que por tanto reintroduce la privacidad como amenaza a la gramática de lo interno y lo externo-, puede presentarse en una forma como la que sigue:

(i) Cuando $S$ sabe que $p$, entonces $S$ sabe que $\sim q$

(Premisa)

(ii) $S$ no sabe que $\sim q$

(Premisa)

(iii) entonces $S$ no sabe que $p$.

Por Modus Tollens de (i)-(ii)

En esta reconstrucción, $S$ representa a un sujeto epistémico, $p$ a una proposición empírica, y $q$ a una proposición que se refiere a un escenario escéptico. El argumento puede instanciarse al caso del fingimiento de la siguiente forma:

(i) $\mathrm{Si} A$ sabe que $B$ tiene dolor, estonces $A$ sabe que $B$ no finge que tiene dolor.

(ii) Pero $A$ no sabe que $B$ no finge que tiene dolor.

(iii) Entonces, $A$ no sabe que $B$ tiene dolor. 
El argumento está constituido por el planteamiento de un escenario escéptico: la puesta en escena de ciertas situaciones en las cuales una pretendida afirmación de conocimiento no puede hacerse. Como ha sugerido Brueckner (ver 1994; 2000), los escenarios escépticos pueden entenderse como contraposibilidades lógicas o epistémicas. En el caso del argumento escéptico del fingimiento, lo que se presenta es un escenario escéptico como una contraposibilidad epistémica: aunque la situación que se pretende conocer se da ( $A$ observa una conducta de dolor en $B$ ), el sujeto no puede llegar a conocerla porque no está justificado (dado que $A$ no sabe si $B$ finge dolor, $A$ no sabe si $B$ tiene dolor).

Habría que notar que el argumento es lógicamente válido, y se apoya en la plausibilidad de sus premisas, las cuales descansan en dos principios epistémicos básicos: el principio de cierre lógico (cuando $S$ sabe que $p$ y $p$ implica $q$, entonces $S$ sabe que $q$ ), y el principio de indeterminación (cuando $p$ y $q$ son contraposibilidades lógicas o epistémicas, no se está justificado para creer que $p$, si la evidencia de la que se dispone permite concluir tanto $p$ como $q$ ). Queda claro, por ejemplo, que la premisa (i) depende del principio de cierre lógico: en efecto, si sé que $B$ tiene dolor, y dado que saber que $B$ tiene dolor excluye el que $B$ esté fingiendo dolor, entonces al saber que $B$ tiene dolor, también sabré que $B$ no está fingiendo dolor. Así podríamos formalizar el principio de cierre lógico:

$(\mathrm{PCL})$

$$
[S p \wedge(p \rightarrow q)] \rightarrow S q
$$

Sin embargo, la critica al PCL es obvia. Ningún sujeto epistémico conoce todas las implicaciones de lo que sabe, pues el principio parece exigir que si se sabe algo, se sepan también todas la implicaciones lógicas que se siguen de lo que 
uno sabe. Esto es simplemente absurdo, y los contraejemplos abundan. Por ello, el principio de cierre lógico tiene que reformularse restringiendo las implicaciones de lo que $S$ conoce. Esta reformulación suele conocerse como el principio de cierre bajo implicación conocida, y es el principio que realmente sustenta las premisas del argumento escéptico:

$(\mathrm{PCL})$

$$
[S p \wedge S(p \rightarrow q)] \rightarrow S q
$$

Una forma de atacar el argumento escéptico consistiría en cuestionar la validez del PCL'. Ello ya lo han tratado de hacer Nozick (ver 1981; 197-247) y Dretske (ver 1970). También es posible usar el mismo PCL' para esgrimir un argumento antiescéptico por medio de un Modus Ponens, como parece que lo hace Moore, y nos lo hace notar Dretske (ver 1970; 34-5). Sin embargo, la vía wittgensteiniana no depende de estas discusiones. Lo que Wittgenstein trata de demoler es el escenario escéptico mismo, aclarando la gramática del fingir, y mostrándonos cómo la posibilidad del fingimiento no constituye una verdadera contraposibilidad epistémica a nuestros usos del lenguaje mental en tercera persona.

2. Wittgenstein y la gramática del fingir

La gramática del fingir wittgensteiniana, que complementa al argumento contra el lenguaje privado, puede delinearse en dos pasos. En este momento sólo delinearé el argumento, y en los apartados posteriores los expondré con mayor detalle.

En un primer momento, Wittgenstein realiza distinciones tanto entre expresiones y observaciones, como entre expresiones auténticas y fingidas. Primero, debemos tener 
en cuenta que la asimetría de lo mental y la privacidad son las características que definen el problema en el argumento contra el lenguaje privado. Por tanto, Wittgenstein analiza la asimetría entre el uso del lenguaje mental en primera y en tercera persona.

Una forma resbaladiza de reductivismo consiste en afirmar que todos los usos del lenguaje mental en primera persona son simétricos a los usos del lenguaje mental en tercera persona; i.e., que toda autoautribución de predicados psicológicos se realiza desde la perspectiva de la tercera persona. Contra esta forma de razonar, Wittgenstein argumenta que el discurso sobre lo interno no puede ser considerado como un reporte o informe; $y$, siguiendo la misma línea argumentativa, sugiere una primera asimetría entre la perspectiva de la primera persona y la perspectiva de la tercera:

La primera persona del singular del presente indicativo se usa claramente de otra forma que la tercera persona o que el pretérito. Juzgamos lo que él hace por su comportamiento, incluyendo lo que dice. La primera persona del singular del presente indicativo no se verifica por una observación de conducta ( $L P P 55)$.

De la asimetría señalada se siguen dos consecuencias: (i) que las autoatribuciones de predicados psicológicos pueden realizarse tanto desde la perspectiva de la primera persona (en presente indicativo), como desde la perspectiva de la tercera persona (al menos, en pretérito); y (ii) que dada la asimetría entre las autoatribuciones y las alioatribuciones, las bases para dichas atribuciones son las que generan la asimetría (en el segundo caso, la observación de la conducta; en el primero, al menos no la observación de la propia conducta). Respecto a (ii), surgen al menos dos problemas: (a) ¿con qué 
base nos autoatribuimos predicados psicológicos?, y (b) ¿qué garantías nos brinda la sola observación de la conducta de los otros para la alioatribución?

Desde la concepcion cartesiana de la mente, parece que si hemos de admitir asimetrías entre el discurso sobre lo interno y sobre lo externo, así como asimetrías entre la perspectiva de la primera y tercera persona, la única explicación de la que disponemos es la diferencia en el acceso que tenemos a nuestros propios fenómenos psicológicos (privilegiado, trasparente, infalible, vía conciencia e introspección), que el que tenemos frente a los fenómenos psicológicos de las otras mentes (vía la sola observación de su conducta; por ende, no privilegiado ni trasparente, y falible). De esta imagen se sigue que mientras sabemos con certeza lo que nos sucede, sólo mediante endebles inferencias podemos adivinar lo que sucede con los otros. De este modo, el escepticismo de otras mentes es el resultado inevitable del cartesianismo. Sin embargo, la opción que se nos presenta inmediatamente contra el cartesianismo no es menos problemática: un conductismo reductivo de lo psicológico que difumina las asimetrías entre el discurso sobre lo interno y sobre lo externo, y entre la perspectiva de la primera y tercera persona.

Frente a posiciones extremas como el cartesianismo y el conductismo, Wittgenstein atiende al sentido de nuestras palabras:

«No puedo saber lo que otro piensa, siente, intenta, etc.» Hay confusión respecto a «no puedo saber». Se podría decir: «Puedo saber, y a menudo sucede, qué piensan otros cuando les duele algo, etc.; y no puedo saber que me duele algo: simplemente me duele algo» $(L P P ; 55)$. 
De esta manera, Wittgenstein argumenta a favor de que, (i) en un sentido básico o primario, no así secundario, las autoatribuciones de predicados psicológicos suelen ser extensiones de (oraciones que reemplazan a) distintas expresiones naturales (e.g., «siento dolor», en algunos casos y contextos básicos, suele ser una extensión de expresiones naturales tales como gemidos o gritos); y, de que (ii) cuando no sé lo que sucede con otro, a pesar de que observo su conducta, esto no se debe a una interioridad que me está velada y de la cual sólo sé ciertas cosas a partir de endebles inferencias, sino a que soy incapaz de leer lo externo.

De lo anterior se sigue una idea muy importante: a saber, que la interioridad (al menos nuestra vieja imagen metafísica y epistémica de la interioridad) es un mito; i.e., la interioridad, como la pensamos, es el resultado de nuestra incapacidad de leer el semblante, los gestos y las circunstancias que están implicados en nuestro uso del lenguaje mental en tercera persona.

¿Es ésta una versión modificada del conductismo? No, pues esto no implica que lo interno termine por reducirse a lo externo; i.e., existe una diferencia entre lo interno y lo externo, pero no una diferencia ontológica ni epistémica, sino sólo conceptual. Wittgenstein tiene muy presente que a la par del argumento contra el lenguaje privado, es necesaria también una clarificación de la gramática de lo interno, la cual viene precedida precisamente del argumento.

Ahora bien, resta la distinción entre expresiones auténticas y fingidas. Dado que la amenaza escéptica se fundamenta en la presunción de la posibilidad omnipresente del fingimiento (i.e., todo uso del lenguaje mental en tercera persona es incierto, pues siempre es posible que el sujeto a quien atribuimos dichos predicados esté fingiendo), Wittgenstein 
argumenta que la misma gramática del fingir implica la existencia de expresiones originales y auténticas (por tanto transparentes y sinceras).

De esto se sigue una consecuencia importantísima: los signos externos no están ligados de la misma manera con las expresiones originales y auténticas que con las fingidas. Por tanto, siempre es posible, si sabemos leer los signos externos, detectar a quien no es sincero. Pero quizá la mayor moraleja de la gramática del fingir wittgensteiniana, en este punto, no sea otra más que ésta: al fingimiento lo define su propósito, y tal propósito está determinado por las prácticas (las cuales, a su vez, constituyen nuestra forma de vida, y se desprenden de nuestra historia natural). Wittgenstein está perfectamente consciente de que el fingir es un juego del lenguaje sumamente complicado, a diferencia del juego del lenguaje de las expresiones originales y auténticas, y que lo fingido se diferencia de lo no fingido fundamentalmente por su propósito.

En este punto, el segundo momento de la gramática del fingir wittgensteiniana se centra en la atribución de estados mentales a otras mentes. El conductismo, que reduce lo interno a lo externo, aceptaría que un joven que grita y llora tiene dolor. Pero este podría estar fingiendo. Por lo que es necesario, en contra del escepticismo de las otras mentes, establecer criterios que nos permitan determinar cuándo finge la otra persona. Para la mayoría, los gritos o las muecas son conductas que expresan dolor. Sin embargo, se podría argumentar que se pueden dar casos en los que estos gestos ocurren y no hay dolor o, a la inversa, que no ocurren y hay dolor. Lo anterior parecería implicar que nunca podemos saber con absoluta certeza si alguien tiene o finge dolor.

Una de las causas para nuestra incertidumbre sobre los estados mentales del otro radica en la vaguedad de nues- 
tros conceptos psicológicos ordinarios. Tampoco existe una «prueba definitiva del fingimiento»; aún así podemos saber cuando alguien está mintiendo, siendo hipócrita o cuando trata de estafarnos. Pero lo que nos permite saber que el otro finge no son datos medibles y definitivos, sino evidencia imponderable: las sutilezas de la mirada, del gesto o del tono de voz, por ejemplo. No existen algo así como «secretos impublicables», pero tampoco existe una medida precisa con la que podamos detectar, sin la intervención de nuestro juicio en cada caso y apelando a innumerables detalles del contexto, que alguien finge. Trabajar adecuadamente con evidencia imponderable implica experiencia y habilidad. El juez con buen ojo (Blick) es quien puede distinguir entre las expresiones sinceras y las mentirosas, entre las auténticas y las fingidas. La moraleja en este segundo momento no es menos relevante: el fingir constituye un paradigma de la imposibilidad de reducir nuestros conceptos psicológicos ordinarios, plagados de vaguedad, a un lenguaje preciso o suficientemente fino. El fingir, paradigmáticamente, sigue el modelo de la evidencia imponderable (unwägbare Evidenz).

Expuestas las líneas básicas del argumento wittgensteiniano, vayamos ya a la argumentación pormenorizada.

\section{Evidencia imponderable}

Iniciemos preguntándonos una vez más: ¿tenemos garantías suficientes para atribuir estados mentales a otras mentes? Si partimos desde el punto de vista escéptico, parece que toda nuestra evidencia - la conducta que observamos- es compatible tanto con un estado mental efectivo como con su fingimiento. La pregunta ahora podría ser: ¿cómo de hecho 
atribuimos estados mentales a otras mentes?, y ¿cuál es en realidad la naturaleza de la evidencia de la que disponemos?

Empecemos por un hecho simple: parece que nuestros conceptos mentales o psicológicos son elásticos, flexibles. Ello no quiere decir - tampoco- que podamos deformarlos a voluntad. Para Wittgenstein, dicha elasticidad es la que los hace utilizables: porque son flexibles cumplen adecuadamente sus propósitos (ver LSPP II 24, 43). Pero avancemos más lento.

Uno de nuestros supuestos ordinarios más comunes es que la incomprensión entre dos individuos se genera porque hay algo oculto en la primera persona - voluntariamente mediante el engaño, incluso involuntariamente por la naturaleza misma de lo interno- desde la perspectiva de la tercera. Wittgenstein nos llama la atención a este respecto:

No se sigue de la falta de fingimiento que cada uno sabe cómo se siente el otro (LSPP II 27).

Considera que nosotros no sólo no entendemos a los demás cuando ocultan sus sentimientos, sino que a menudo también cuando no los ocultan, incluso cuando hacen todo lo posible para hacerse entender (LSPP II 28).

Alguien podría pensar: o bien es lo interno, en tanto interno, lo que causa nuestra incomprensión; o bien es que los otros desean ocultarme sus estados mentales. En el primer caso, la incomprensión sería el resultado de la naturaleza misma de lo mental; en el segundo, sería una posibilidad práctica presente en cada caso. En otras palabras, cualquier conducta que yo observase sería compatible con el hecho de que el otro esté fingiendo. Sin embargo, ni es lo interno lo que me 
está oculto en tanto interno ${ }^{4}$, ni la conducta del otro es compatible siempre con el hecho de que esté fingiendo - incluso de que no finja no se sigue que lo comprendo-. Estas dos tesis wittgensteinianas serán nuestro punto de partida.

Primero, Wittgenstein niega que la incomprensión sea fruto de un sentido de ocultamiento de lo interno: incluso cuando trato de hacerme entender, de cualquier forma y por todos los medios, cabe la posibilidad de que el otro no me comprenda. Es la flexibilidad de nuestro lenguaje psicológico la que - paradójicamente- hace que nos comprendamos en ocasiones, y en ocasiones no. Así, no es una clausura metafísica - ni, como veremos un poco después, que los otros siempre puedan engañarme- la causante de nuestra incertidumbre ante las otras mentes, sino la naturaleza misma de nuestro lenguaje y su conexión con la conducta. De este modo lo señala el propio Wittgenstein: «La inseguridad, que siempre existe, no es la de si quizás finge (pues él podría incluso figurarse que finge), sino más bien la complicada conexión de las palabras «tener dolor» con la conducta humana» (LSPP II 30).

Ahora bien, preguntémonos: ¿sería posible anular dicha elasticistad y flexibilidad de nuestro lenguaje? Supongamos que pudiéramos disponer de criterios objetivos y claramente estipulados para medir la presencia efectiva de estados mentales. Imaginemos una forma de vida distinta donde los

\footnotetext{
${ }^{4}$ Wittgenstein niega esta posibilidad al analogar el sentido en el que el futuro me está oculto, con el sentido en el que lo interno me está oculto: «El pensar del hombre acontece en el interior de la conciencia en una clausura suya; en comparación con ella cualquier clausura física es apertura. / El futuro nos está oculto. Pero ¿piensa así el astrónomo que calcula un eclipse de Sol? / Lo interno está oculto. - El futuro está oculto» (LSPP II 21)
} 
[...] humanos han desarrollado un aparato para medir el dolor llamémoslo «algímetro»— que tiene un aspecto semejante a nuestros manómetros efectivos. Aplicado a uno de nosotros, las oscilaciones de la aguja señalan determinado número de «algias», como vamos a llamar a esta fantástica unidad de dolor. En este caso, los criterios para decidir si alguien tiene o no dolor, si lo simula [finge] o no, y muchas otras cosas, estarían bien definidos. Cuando la aguja señala determinado número de algias por encima del umbral de percepción diremos que el individuo en cuestión tiene inequívocamente dolor. Para ser exactos, diríamos que el sujeto $X$ tiene en un momento determinado y número de algias (Valdés 1996; xxvi) .

En este supuesto, contaríamos con un vocabulario mental definido que «aparentemente» nos libraría de manera definitiva de la posibilidad de la inadvertencia del fingimiento del otro y, por tanto, del escepticismo de otras mentes. Sin embargo, atendamos a varias posibilidades. Primero, aunque el «algímetro» realmente existiera, y otros instrumentos para medir los distintos estados mentales, ¿realmente estaríamos hablando aquí de dolores (de «nuestros» dolores ${ }^{6}$ )? Sí respondemos afirmativamente, tendríamos que admitir la siguiente posibilidad: que una persona que se retuerce de dolor no lo tiene porque el algímetro no lo señala, y actuar en consecuencia. Tendríamos que dejar al susodicho retorcerse de dolor, sin prestar auxilio: pues el algímetro nos ha dicho fuera de toda duda que el sujeto no tiene dolor. Sin embargo,

\footnotetext{
${ }^{5}$ Este ejemplo de Valdés está inspirado en una anotación del propio Wittgenstein: «Podría pensarse en una especie de termómetro para averiguar si alguien tiene dolor. Si un hombre grita o gime, entonces le ponen el termómetro y sólo cuando señala esta o aquella oscilación empiezan a sentir compasión por el que sufre y a tratarlo como nosotros hacemos con quien «obviamente tiene dolor»» (LSPP II 93). ${ }^{6}$ Podríamos quizá aceptar que estos serían dolores, pero no serían nuestros dolores; i.e., tendríamos que redefinir por completo el concepto mismo de dolor, y ello cambiaría por completo nuestras prácticas, por ende nuestra forma de vida tal cual nos la figuramos ahora.
} 
no lo hacemos así ordinariamente. Cuando vemos una escena como la anterior prestamos auxilio sin pensarlo.

Parece que, aunque dispusiéramos de criterios muy definidos, eso no nos libraría de problemas. Ahora bien, aunque fuese posible medir, ¿tendría tal medición alguna importancia? Wittgenstein es muy claro al respecto: «Allí donde el medir no es importante no medimos, incluso si podemos hacerlo» (LSPP II 94). A pesar de lo que alguno pudiera pensar, Wittgenstein cree que la flexibilidad de nuestro vocabulario mental no es producto de una fase primitiva de nuestro desarrollo. La forma de vida humana misma es incierta. Lo que nos muestra la incertidumbre en la alioadscripción de estados mentales es que la vida misma es impredecible. Ahora bien, ¿podríamos ser de otro modo?, ¿podríamos imaginarnos usando algímetros y otros instrumentos para alioadscribir estados mentales? Y, si pudiéramos, ¿cambiaríamos nuestra forma de vida? ¿Cómo podríamos responder a ello? Wittgenstein trata de derrumbar este supuesto.

En principio, la posibilidad misma de fingir estados mentales — también de mentir, imitar, disimular, exagerar, ser hipócrita, etc.- delinea la vida humana. Pensar que sería posible eliminar la posibilidad de fingir consistiría en imaginar una forma de vida completamente distinta:

Pero piensa ahora en que llegases a una sociedad en la que, como podríamos decir, los sentimientos se reconocen con seguridad a partir de las apariencias (no usamos la figura de lo externo y de lo interno). Pero ¿no sería esto similar a llegar, desde un país en el que se llevan muchas máscaras, a otro en el que no se lleva ninguna o se llevan muy pocas? (Algo así como ir de Inglaterra a Irlanda). La vida es aquí simplemente distinta (MS 169, 28; LSPP II 28). 
Wittgenstein es conservador. Lo que le interesa es describir nuestra forma de vida, no reformarla. Cualquier intento por eliminar la posibilidad del fingimiento de la misma - parece pensarimplicaría figurarse una vida distinta. Además, — piensa- el fingimiento (su posibilidad), es la que está detrás de la fabulación, la imaginación, la representación de un papel, etc. Gracias a que podemos fingir estados mentales, también somos capaces de participar en prácticas que son consideradas deseables. Eliminar la posibilidad de fingir sería a su vez eliminar un sinnúmero de prácticas humanas. Por ello, Wittgenstein no considera esta ambición antiescéptica positiva por sí misma. Así lo expresa de manera contundente:

Una tribu en la que nadie finge jamás, o en la que es algo tan raro como que entre nosotros uno ande por la calle a gatas. De hecho, si alguien aconsejase fingir a otro, se comportaría más o menos como uno de nosotros al que se le recomienda andar a gatas. Pero ¿qué sigue? No hay aquí tampoco ninguna confianza. Y la vida entera parece completamente distinta pero, de acuerdo con esto, no necesariamente más bonita de modo global (LSPP II 27).

Prácticas como la confianza en otros, la empatía o antipatía entre los individuos y lo que comparten entre ellos, las preferencias personales en ciertos usos no literales del lenguaje, la ritualística religiosa, todo ello quedaría eliminado de la vida humana. En efecto, en dicha tribu imaginaria no habría posibilidad de engaño, pero Wittgenstein lo deja claro: la vida sería distinta, no por ello mejor, más deseable.

Otro asunto queda en el tintero: de hecho la flexibilidad de nuestro lenguaje mental es el que logra que cumplamos los propósitos para los que lo usamos. No usamos conceptos más simples porque no nos «interesa». Nuestros conceptos están 
determinados por nuestros intereses, por tanto por nuestro modo de vida (LSPP II 43). Imaginemos el siguiente escenario: Juan escribe una carta a Isabel en la que le declara su amor. Dicha carta podría adoptar la forma discursiva de un memorando o de prosa poética. En el primer caso, Juan establecería de manera lo más precisa posible sus intenciones, y las responsabilidades mutuas que ambos tienen si Isabel aceptara su declaración. En el segundo caso, Juan — seguramente mediante metáforas que conoce - trataría de hacerle ver sus sentimientos. ¿Qué forma discursiva cumple mejor con los propósitos de Juan? Esto dependerá seguramente de su personalidad. El punto es que no puede intercambiar palabras flexibles por precisas a voluntad. Unas cumplen mejor sus propósitos que otras. Sus conceptos — como los nuestros- están determinados por sus intereses ${ }^{7}$.

Volvamos ahora a la pregunta con la que comenzamos este apartado y demos un paso más: ¿tenemos garantías - $\mathrm{y}$, de ser el caso, de qué tipo- para atribuir estados mentales a otros? Wittgenstein, más que buscar una refutación del planteamiento escéptico, tratará de explicitar la gramática de dichas atribuciones:

Y queda ahora la pregunta de si nos desharíamos de nuestro juego del lenguaje que se basa en la «evidencia imponderable» y conduce a menudo a la inseguridad, si tuviéramos la posibilidad de cambiarlo por uno más exacto que tuviese, en general, similares consecuencias. Podríamos — por ejemplo- trabajar con un «detector de mentiras» mecánico y volver a definir una mentira

\footnotetext{
${ }_{7}$ Wittgenstein es claro a este respecto: ¡Piensa sólo en las palabras que los amantes se dicen mutuamente! Están «cargadas» de sentimiento. Y seguramente no son intercambiables por otras ristras de sonidos cualesquiera a voluntad» (LSPP II 17).
} 
como aquello que produce una oscilación en el detector de mentiras. / Así pues, la pregunta es: ¿Cambiaríamos nuestra forma de vida si esto y aquello se pusiera a nuestra disposición? - ¿Y cómo podría responder a esto? (LSPP II 95).

Su planteamiento parte de la siguiente tesis: aunque no poseemos evidencia «ponderable» suficiente-y si dispusiéramos de ella, parece que no la utilizaríamos ordinariamente- para saber con certeza que alguien tiene dolor, sí poseemos evidencia «imponderable» (unwägbare Evidenz) para alioadscribir estados mentales. En otras palabras, aunque la ocurrencia de cualesquiera criterios no es incompatible con el fingimiento, poseemos evidencia de cierto tipo que nos permite advertir ${ }^{8}$ que alguien está fingiendo o no lo está. Ahora bien, ¿a qué nos referimos cuando atribuimos el calificativo de «imponderable» a cierto tipo de «evidencia»? En un sentido ordinario, decimos que algo es imponderable cuando no es sujeto de medición precisa - por tanto, que excede toda ponderación-, cuando no es previsible y sus consecuencias no pueden estimarse. Ya encontramos una referencia a la evidencia imponderable en las Investigaciones:

La cuestión es: ¿Qué efectúa la evidencia imponderable? / Supón que hubiera evidencia imponderable de la estructura química (el interior) de una sustancia; con todo tendría que mostrarse como tal evidencia a través de ciertas consecuencias ponderables (wägbare). / (La evidencia imponderable puede convencer a alguien de

\footnotetext{
${ }^{8}$ Es difícil nombrar con algún verbo lo que sucede con respecto a la evidencia imponderable, de la que en ocasiones disponemos, para decir que alguien finge o no lo hace. Podríamos usar un verbo, muchas veces peligroso, como es intuir. U otro, quizá mucho más complicado respecto a sus implicaciones epistemológicas, como percibir. Prefiero un verbo más indeterminado, y con muchas menos connotaciones ideológicas y filosóficas como advertir, aunque también podríamos usar distinguir, notar o reparar.
} 
que esta figura es auténtica... Pero esto también puede resultar ser correcto por medios documentales). / Entre la evidencia imponderable se cuenta con las sutilezas de la mirada (die Feinheiten des Blicks), del gesto (der Gebärde), del tono de la voz (des Tons). / Puedo reconocer la mirada auténtica del amor, distinguirla de la falsa (y naturalmente puede haber aquí una confirmación 'ponderable' de mi juicio). Pero puedo ser completamente incapaz de describir la diferencia. Y esto no es por la razón de que las lenguas que conozco carecen de las palabras para ello. ¿Por qué no introduzco simplemente nuevas palabras? - Si yo fuera un pintor de extraordinario talento, sería imaginable que pudiera representar en figuras la mirada auténtica (den echten Blick) y la hipócrita (den geheuchelten darstellte). / Pregúntate: ¿Cómo aprende un ser humano a tener «buen ojo» (Blick) para algo? ¿Y cómo se puede emplear ese buen ojo? (PU II 194).

El texto citado de las Investigaciones nos da ya muchas pistas para interpretar la postura wittgensteiniana con respecto a la gramática de las atribuciones de estados mentales a otras mentes. Por un lado, Wittgenstein parece negar que sea posible advertir «siempre» — no como una cuestión lógica, sino empírica- que alguien finge. No existiría en la práctica algo así como la «prueba definitiva del fingimiento». Careceríamos de los medios para saberlo fuera de toda duda ${ }^{10}$. Sin

\footnotetext{
${ }^{9}$ Cito la segunda parte de las Investigaciones a partir de la tercera edición inglesa de 2002.

${ }^{10}$ Este problema ha recibido una atención primordial de parte de la psicología en las últimas décadas. Paul Ekman, a partir de los desarrollos de Darwin (1872), ha estudiado la universalidad de las emociones, a partir de las expresiones faciales, como un criterio para detectar el engaño. Sin embargo, esto no pondría en cuestión la gramática wittgensteiniana. Ekman considera que a pesar de que dispongamos de dichos criterios, muchas veces de hecho somos engañados (ver 1996), además de que lo que ordinariamente nos importa no es tanto si alguien nos engaña, sino el por qué lo hace (ver 1985). Lo segundo es imposible determinarlo de manera contundente a partir de las expresiones faciales. Además, los criterios de Ekman de hecho son compatibles con la gramática de Wittgenstein: es la evidencia imponderable de las expresiones faciales, y no la evidencia ponderable de un detector de mentiras, lo que evolutivamente nos ha equipado para poder detectar el engaño.
} 
embargo, es posible en muchos casos advertir que alguien finge. Sabemos muchas veces que el otro es un hipócrita, falsario, embustero, farsante. ¿Qué nos hace advertirlo? Ciertos detalles que muchas veces no tienen forma de ser ponderados:

Ahora bien, por ejemplo, he visto la mirada que uno le ha echado a otro. Y digo: «Si tú lo hubieses visto habrías dicho lo mismo» (Pero aquí hay todavía oscuridad). Tal vez en otra ocasión pueda conseguir que perciba esta mirada, y entonces se convencerá. Esto sería una posibilidad. (LSPP I 923).

El que dispongamos de dicha evidencia imponderable muestra que el fingimiento no es una posibilidad que clausure mi advertencia de la misma. Tampoco existen algo así como «secretos impublicables». Si existe la posibilidad de que advierta la condición fraudulenta de las expresiones del otro - al menos en ciertas ocasiones-, el escepticismo de otras mentes no parecería una postura teóricamente generalizable.

Dando un paso más adelante, Wittgenstein afirma que ciertas sutilezas de la mirada, del gesto y del tono de voz nos pueden llevar a advertir que el otro finge. De manera inversa, también nos pueden llevar a concluir que el otro es sincero. El proceso muchas veces nos pasa desapercibido: cuando no existe razón alguna para suponer que el otro finge, ordinariamente damos por sinceras sus expresiones. Sólo en estos casos, aunque son de lo más frecuentes, podemos decir que lo interno es externo - de la forma en que lo afirma el conductismo lógico, aunque dicha postura generaliza esta posibilidad-. Wittgenstein así lo indica, y se distancia de la radicalidad tanto de la concepción cartesiana de la mente como del conductismo lógico: 
Cuando semblante, gesto y circunstancias son inequívocos, entonces parece que lo interno es externo; sólo cuando no podemos leer lo externo parece que algo interno se esconde tras de ello (LSPP II 63).

Pero, aún nos queda un asunto por resolver. ¿Qué necesitamos para evaluar la evidencia imponderable? $\mathrm{O}$, mejor dicho, ¿qué nos hace falta para advertir que alguien finge o es sincero a partir de dicha evidencia?, o ¿cómo somos capaces de advertir la presencia de evidencia imponderable? Wittgenstein habla de «buen ojo» (Blick), pero esto no nos dice mucho. ¿Acaso se puede aprender esta capacidad? O bien, ¿qué nos muestra que Wittgenstein hable de una posibilidad tan ambigua como puede ser este supuesto «buen ojo»? Darwin se había percatado que los seres humanos estamos equipados evolutivamente con la capacidad para evaluar emociones a partir de expresiones faciales (1872), sin embargo cabe también la posibilidad de que dicha capacidad pueda desarrollarse a lo largo de una vida.

Desde una perspectiva wittgensteiniana, atendamos a la primera parte de los cuestionamientos. Wittgenstein responde con una interesante analogía:

Aquí hay un hecho importante, que aprendemos solamente a través de una larga experiencia y no por medio de un curso escolar. ¿Cómo se desarrolla, por ejemplo, el ojo del entendido: «Este cuadro no es de este o aquel maestro»? — de este modo se hace una afirmación que no es un juicio estético, pero que tal vez puede probarse por medio de documentos. / Él puede no estar en situación de fundamentar su juicio claramente. - ¿Cómo lo ha aprendido? ¿Podría habérselo enseñado alguien? Por supuesto. -No de la misma manera como se aprende a calcular. Es ne- 
cesaria mucha experiencia. Esto es, el aprendiz tal vez tiene que contemplar y comparar una y otra vez gran número de cuadros de distintos maestros. Al hacerlo así se le podrían haber hecho indicaciones. Bien, ése fue el proceso de aprendizaje. Después contempla un cuadro y hace un juicio. En muchos casos podría señalar razones para su juicio, pero la mayoría de las veces no serán éstas convincentes (LSPP I 925).

Si nos detenemos en la analogía anterior, ésta resulta clarificadora. Así como un curador emite un juicio sobre la posible autoría de un cuadro, nosotros atribuimos estados mentales a otros. En algunas ocasiones disponemos de evidencia que podemos señalar para hacerlo. Podemos atender a su conducta explícita, y podemos relacionarla con cierto concepto que tenemos de los estados mentales que le atribuimos. A veces esto no es posible. Lo hacemos de manera espontánea y natural: podemos señalar algo, y muchas veces no podemos señalar nada. Esta capacidad, aunque natural y fruto de nuestra historia evolutiva, se desarrolla a través de una larga experiencia.

En resumen, esta especie de «sensibilidad» para advertir mediante evidencia ponderable (pero la mayoría de las veces insuficiente) o imponderable, que el otro finge o es sincero, es un asunto difícilmente tematizable. Esta sensibilidad puede desarrollarse, pero su proceso de desarrollo tiene características muy específicas: podría decirse que mediante la experiencia en nuestro trato con seres humanos vamos adquiriendo tal habilidad. Aunque el proceso que nos lleva al juicio dista mucho de ser un proceso discursivo. Las más de las veces, por eso la evidencia con la que contamos es imponderable, no tenemos ninguna razón que podamos explicitar para dar cuenta de nuestra atribución. 
Eso nos lleva a la respuesta al segundo cuestionamiento. Wittgenstein nos intenta mostrar que nuestras atribuciones ordinarias de estados mentales a otros es incompatible con una racionalidad austera — propia del cálculo- . La «inseguridad» en el proceso de atribución es esencial al mismo, y el proceso mediante el cual lo hacemos tiene múltiples aristas no tematizables (aunque posiblemente figurables o descriptibles).

\section{Gramática del fingimiento}

Antes de dar un paso más en mi argumentación, resulta necesario hacer unas cuantas precisiones terminológicas. Wittgenstein usa casi de manera sinónima dos verbos para referirse a la misma acción: heucheln y verstellen. Las traducciones al castellano hacen muchas veces estragos. Traducen heucheIn por fingir, al igual que disimular o simular (aunque en sentido estricto convendría traducirlo por «ser hipócrita»); y verstellen por simular, al igual que disimular o fingir. En castellano la connotación de estos términos no nos hace posible tratarlos como simples sinónimos. Por ejemplo, usamos «fingir» para nombrar un acto predominantemente humano - aunque por analogía podemos decir que los animales fingen-. Así, no podemos decir, en sentido estricto, que una máquina «finge». Por el contrario, sí podemos decir que un máquina «simula»" El verbo «disimular», por su parte, suele ser aplicado a los ca-

\footnotetext{
${ }^{11}$ Esto no está recogido en el Diccionario de la RAE. Sin embargo, creo oportuna la distinción. Simular, aunque puede ser un verbo que usemos para describir lo que hacen los actores, no es común que lo usemos para los embaucadores. La razón es simple: el juego del lenguaje del fingir es más complicado que el de simular, pues el primero implica la intención de engañar, mientras que en el segundo caso nadie es engañado. Por ello los animales no pueden fingir en sentido estricto, mucho menos las máquinas.
} 
sos en que un ser humano trata de aparentar que no siente lo que siente ${ }^{12}$; a diferencia de «fingir», que suele ser aplicado a la inversa, para los casos en que un ser humano trata de aparentar que siente lo que no siente ${ }^{13}$. Wittgenstein se centra casi de manera exclusiva en los casos en los que alguien finge, y no en casos generales de simulación, o casos específicos de disimulo.

Ahora bien, como mencioné en el primer apartado, el escéptico utiliza el caso del fingimiento como el paradigma para dar cuenta de que tras la manifestación externa -la conducta - se oculta algo interno. Si la gramática del fingimiento nos hace necesario usar la dicotomía interno/ externo para dar cuenta de su lógica, entonces resultará imposible desembarazarnos de dicha dicotomía en nuestra concepción de la mente. Si ello no es así, podríamos pensar que dicha dicotomía será inoperante para lo mental en su conjunto. Pues, ¿en qué consiste fingir? ¿Cuál es su gramática?

La respuesta a la pregunta anterior, desde la concepción cartesiana de la mente, es de una economía didáctica sorprendente. Supongamos que un sujeto $A$ tiene una sensación $y$, y la manifiesta con ciertos criterios $z$. Ahora bien, ¿en qué se diferencia este sujeto con alguien que simplemente finge el estado mental? Desde el cartesianismo la respuesta es simple: un sujeto $B$ no tiene una sensación $y$, a pesar de ello la manifiesta con ciertos criterios $z$. La única diferencia, como se puede ver, es que en la expresión original y auténtica no se oculta algo interno mediante lo externo, y en la fingida sí. Por ello, no hay diferencia en la manifestación externa, en

\footnotetext{
${ }^{12}$ Así lo indican el primer, tercer y quinto sentido que se señalan en el Diccionario de la $R A E\left(22^{\mathrm{a}}\right.$ ed.): «Encubrir con astucia la intención», «Ocultar, encubrir algo que se siente o padece», «Disfrazar u ocultar algo, para que parezca distinto de lo que es».

${ }^{13}$ Así lo indica el primer sentido que se señala en el Diccionario de la $R A E\left(22^{\mathrm{a}}\right.$ ed.): «Dar a entender lo que no es cierto».
} 
los signos del dolor, sino sólo en la relación de ésta con la ocurrencia o no ocurrencia interna de cierto estado interno. Parecería, por decirlo de una manera más simple, que tanto la expresión original como el fingimiento son opciones paralelas que pertenecen a un mismo juego del lenguaje, pero que difieren en su referencia. La dicotomía interno/externo se vuelve de una importancia superlativa para su explicación de este caso paradigmático, por lo que serviría también para dar cuenta de lo mental en su conjunto.

El procedimiento wittgensteiniano consistirá en plantear ciertas interrogantes respecto a casos límite para forzar al máximo la respuesta cartesiana. Después de dicho ejercicio, se pondrá en cuestión un supuesto bastante ordinario mediante el cual entendemos lo mental. El caso límite será el recién nacido. Pues, como se podrá advertir, dado que el juego del lenguaje del fingimiento no es el mismo que el de la expresión original — como supone el que adopta la concepción cartesiana de la mente-, sino que es mucho más complejo, el niño aprende a fingir, mientras que no necesita aprender simplemente a expresarse. Así comienza Wittgenstein su gramática:

Si el fingir no fuese un modelo tan complicado, sería pensable que el recién nacido finge [...] / Pero supongamos que el niño pudiese fingir desde el primer instante en que llega al mundo, es más: que su primera emisión de dolor es fingida. —Podríamos imaginarnos una actitud de desconfianza hacia el recién nacido: pero ¿cómo le enseñaríamos la palabra «dolor» (o «pupa»)? (LSPP II 55).

El planteamiento anterior nos lleva ya a una primera y determinante conclusión: «Diré, por lo tanto, que hay una ex- 
presión de dolor original y auténtica; que, por lo tanto, la expresión de dolor no está ligada de la misma manera con el dolor y al fingimiento» (LSPP II 55). Por decirlo de otra manera, los signos externos del dolor en el caso de la expresión original y en el caso de la fingida no son siempre los mismos, sino sería imposible atrapar al embaucador. Dado que es posible, y no necesariamente excepcional, que advirtamos que alguien finge, los signos externos del fingimiento no pueden ser exactamente los mismos que en el caso de la expresión original ${ }^{14}$. En segundo lugar, la expresión original, se ve de manera paradigmática en el caso del recién nacido, no es un informe acerca de un estado interno del emisor, sino simplemente una expresión natural. Sólo si suponemos que oraciones del tipo «Tengo dolor» tienen originalmente - en un sentido básico - un valor cognitivo, surgen los problemas en torno al fingimiento, y con ello la dicotomía interno/externo para dar cuenta de lo mental.

Ahora bien, si fingimiento y expresión original son dos juegos del lenguaje distintos y, por tanto, tienen rasgos fundamentalmente distintos, ¿en qué consiste propiamente el juego del lenguaje del fingir? Aquí sí habría que apelar al aprendizaje mismo del fingimiento, pues ¿cómo aprende un niño a fingir? Wittgenstein lo describe así:

¿Qué tiene que aprender un niño antes que pueda fingir? Por ejemplo, el uso de las palabras como: «El cree que siento dolor, pero yo no lo tengo» (LSPP I 866).

\footnotetext{
${ }^{14}$ Ésta es la sorprendente conclusión a la que ha llegado Paul Ekman (1985) con sus estudios sobre las microexpresiones: el rostro traiciona cualquier verbalización, y mediante expresiones que duran una fracción de segundo podemos saber qué emociones se tratan de fingir o disimular.
} 
Un niño experimenta que se le trata mejor cuando, v. gr., tiene dolores si llora; comienza a llorar para que lo traten así. Esto no es fingir. Sólo una raíz de la hipocresía (LSPP I 867).

Un niño tiene que aprender muchas cosas antes de poder fingir. (LSPP I 868).

Tiene que aprender un modelo complicado de conducta antes que pueda fingir o ser sincero (LSPP I 869).

El niño aprende también a imitar el dolor. Aprende el juego: actuar como si tuviese dolores (LSPP I 871).

«Una vez que conoce el niño lo que es el dolor, también conoce, naturalmente, que el dolor puede fingirse» (LSPP I 872).

Así pues, vemos que el niño tiene que aprender muchas cosas antes de poder fingir un estado mental. En primer lugar, un modelo de complicado de conducta, el uso de ciertas palabras, la capacidad de imitar estados mentales, etcétera. En cambio, resulta evidente que sus expresiones naturales no son aprendidas: en cierto sentido podríamos decir que son «naturales» $\mathrm{o}$ «animales».

Además, no debemos confundir la «hipocresía» con el fingimiento. Alguien es hipócrita cuando actúa de determinada forma con ciertos objetivos - el niño llora para que lo mimen-, pero la simple hipocresía está lejos de poder ser considerada fingimiento. Alguien finge, básicamente, cuando tiene intención de engañar al otro: cuando trato de hacerle creer ciertas cosas que yo creo que no son ciertas.

El niño que llora para que lo mime su madre no busca engañar a su madre, simplemente busca que lo mimen. En cambio, el niño que gime de dolor de estómago por la mañana para no ir a la escuela a presentar el examen para el que 
no estudió, busca que su madre crea algo que él sabe que no es verdad: que realmente tiene dolor de estómago. Por tanto, es necesario saber imitar estados mentales - por ejemplo, dolores de estómago-, entender el uso de palabras como «él cree $x$, aunque yo sé que no es así», etcétera, para poder decir que es posible el fingimiento. Con ello queda claro que el juego del lenguaje del fingimiento es radicalmente más complejo que el de las expresiones originales y auténticas. La conclusión, hasta este punto, resulta obvia:

Pero este nuevo juego del lenguaje no funciona al mismo nivel lógico, esto es: no tiene las mismas relaciones y consecuencias que el juego del lenguaje en el que sólo se puede expresar dolor auténtico. Así pues, el problema de la simulación [fingimiento] no es primariamente epistemológico, sino algo que tiene que ver con la relación entre los distintos juegos del lenguaje (Valdés 1996; xxii-xxiii).

A pesar del interesantísimo viraje lingüístico que Wittgenstein realiza respecto al problema del fingimiento, antaño un problema considerado desde una óptica fundamentalmente epistémica, este tampoco elimina -como sugerimos en el apartado anterior - nuestra incertidumbre frente a las otras mentes. Las razones son varias.

En primer lugar — recordemos-, no se sigue de la falta de fingimiento que cada uno sabe cómo se siente el otro. En otras palabras, aunque fuese desterrado el fingimiento de la forma de vida humana, de ello no se seguiría que todos nos comprendiésemos de manera perfecta, pues los errores de comprensión están a la vuelta de la esquina. Podríamos decir: «Aunque sé que no finge, no sé qué es lo que le sucede». En segundo lugar, las prácticas del 
fingimiento no son resultado de un defecto de la forma de vida humana, sino simplemente una de sus tantas características.

\section{Actitudes y opiniones}

Para terminar la caracterización wittgensteiniana, sólo resta afirmar que la relación del yo consigo mismo no parece ser fundamentalmente epistémica, como tampoco lo es la relación del yo con el otro. La única forma de superar el escepticismo de otras mentes, no así de refutarlo ${ }^{15}$, es salir de la perspectiva epistémica ${ }^{16}$.

Respecto a esto último, resulta de la mayor utilidad la distinción wittgensteiniana entre actitud (Einstellung) y opinión (Meinung). Por ejemplo, aunque estemos inciertos epistémicamente de que alguien esté triste - no porque su expresión sea poco clara, sino por la incertidumbre misma en la alioatribución de estados mentales-, eso no quiere decir que en la práctica se presente dicha incertidumbre. Cuando tratamos con otros seres humanos no experimentamos ordinariamente incertidumbre epistémica respecto de sus estados mentales. La amenaza del escepticismo de otras mentes es fundamentalmente teórica, no práctica. Cuando el otro me expresa su tristeza, yo no suelo adoptar una opinión al respecto - a menos que se presente una anomalía-, sino que tomo cierta actitud ante ella. Así reza la formulación wittgensteiniana en las Investigaciones:

\footnotetext{
${ }^{15}$ Pues esto sería permanecer dentro de la misma perspectiva epistémica.

${ }^{16}$ Algo similar propone Scruton, también desde una perspectiva wittgensteiniana; (ver 1995, 48-50).
} 
Mi actitud hacia él es una actitud hacia un alma (Meine Einstellung zu ihm ist eine Einstellung zur Seele). No tengo la opinión de que tiene un alma (Ich habe nicht die Meinung, daß er eine Seele hat) (PU II 152).

Justamente el giro que propone Wittgenstein se garantiza por las connotaciones tanto de «opinión» como de «actitud». Una opinión es un estado epistémico. Por el contrario, «actitud» tiene una clara connotación «práctica», no «teórica». Ahora bien, ¿acaso no las actitudes provienen o son el resultado de opiniones? Wittgenstein es muy claro al respecto:

En lugar de «actitud hacia el alma» podría decirse también: «actitud hacia el hombre». / Siempre podría decir de un hombre que es un autómata (podría aprender esto en la escuela, en las clases de fisiología) y, sin embargo, esto no influiría en mi actitud hacia los demás. Incluso puedo decirlo de mí mismo. / Pero ¿cuál es la diferencia entre una actitud y una opinión? Yo diría: la actitud viene antes de la opinión (LSPP II 38).

El malentendido surge debido a que cuando algo no sale bien modificamos —o sería plausible que modificáramosnuestras actitudes hacia el otro. Cuando sospecho que finge, bien puedo tomar precauciones en mi respuesta. Quizá le brinde consuelo, pero no estaré sometido a sus caprichos. Sin embargo, cuando no se presentan anomalías, no tenemos opiniones sino que tomamos actitudes frente a los estados mentales del otro. La actitud - naturalmente- viene antes que la opinión.

Por ello, bien podríamos decir que el escepticismo de otras mentes surge cuando confundimos actitudes y opiniones, o tomamos las unas por las otras. Esto quiere que el es- 
cepticismo de otras mentes no es una postura que quepa generalizar teórica ni prácticamente. Aunque con ello tampoco podemos decir que nos hemos salvado de la incertidumbre. Quizá sea Cavell quien de mejor de manera ha interpretado este punto. Para él, nadie ni nada nos releva de nuestra responsabilidad frente al otro: ni los criterios ni su ausencia. No hay algo que nos permita acceder al otro de manera completa y total, ni tampoco hay nada que nos lo impida de manera definitiva:

Ahora podemos ver algo más de lo que se expresa en el mito del cuerpo como algo que vela o esconde la mente. Algo está velado -la mente por sí misma-. Pero la idea del cuerpo desempeña su papel. En la fantasía del cuerpo como algo que vela, es él lo que se interpone entre mi mente y la del otro, lo que nos separa. Aquí, la verdad estriba en que estamos separados, pero no necesariamente separados (por algo); estriba en que somos, cada uno de nosotros, cuerpos, i.e., encarnados; cada cual es éste y no aquél, cada cual aquí y no allí, cada cual ahora y no entonces. Si algo nos separa, se interpone entre nosotros, eso sólo puede ser un aspecto o una postura particular de la mente misma, una forma particular de relacionarnos, o en la que estamos mutuamente relacionados (por nacimiento, por la ley, por la fuerza, en el amor) -nuestras posiciones, nuestras actitudes, el uno respecto al otro. Llámese a esto nuestra historia. Es nuestro presente (1979; 368).

El otro es alguien al que yo respondo, y puedo hacerlo responsable o irresponsablemente. Esto es posible sólo si superamos la perspectiva epistémica, y sólo si aceptamos nuestra separación, no como algo remediable, o bien irreparable, sino como un hecho constitutivo de nuestra condición. 
Hasta este punto, parece que hemos llegado a una conclusión negativa, pero con ello ya hay cierto avance. Valdés la formula así en su estudio introductorio al segundo volumen de los Últimos escritos sobre Filosofía de la Psicología:

[...] todo el libro es un espléndido viaje a través del juego del lenguaje de los conceptos psicológicos, donde se nos va mostrando hasta qué punto son falsas e ilusorias las figuras que habitualmente nos hacemos de lo mental. A la vez se nos muestra cómo tales figuras nos impiden hacer el esfuerzo necesario para comprender la abrumadora complejidad de lo mental y nos invitan a mirar hacia el lado equivocado [...] miramos hacia un pretendido interior del sujeto como aquello que nos ha de proporcionar la clave sin darnos cuenta de que es en la complejidad de la vida humana donde está el escenario en el que se desarrolla el juego del lenguaje de los conceptos psicológicos (1996; x-xi).

Así, no caben los reduccionismos ni los simplismos didácticos para dar cuenta de lo mental. Por un lado, la concepción cartesiana de la mente falla, pues supone que la dicotomía interno/externo nos proporciona la clave para entender lo mental.

Sin embargo, el fingir no se explica a partir de la idea de que algo interno se oculta tras algo externo, pues se trata de un juego del lenguaje bastante complejo, muy distinto al juego del lenguaje de las expresiones originales y auténticas. El conductismo - su antítesis - tampoco funciona: al reducir lo interno a lo externo, termina por desdibujar las asimetrías entre la perspectiva de la primera y tercera personas, y minimiza nuestra incertidumbre ante las otras mentes. Es conocido el pomposo slogan ryleano: «Dejar a un lado las es- 
peranzas del Acceso Privilegiado es, también, dejar a un lado el temor del aislacionismo cognoscitivo; perdemos el gusto amargo del Solipsismo junto con su dulzura» (1949; 138). Sin embargo, aunque Ryle pretende salvarnos del aislamiento epistémico, no termina por erradicar nuestra incertidumbre respecto a las otras mentes. Ni la concepción cartesiana de la mente ni el conductismo lógico dan cuenta de las complejidades de lo mental.

A continuación -y para finalizar-, atenderé a algunas posibles objeciones que podrían hacerse a la gramática wittgensteiniana del fingir: en particular, algunas que se desprenden de algunas consideraciones de Ryle.

Ryle y el fingimiento

Uno de los primeros mapas trazados sobre el entorno conceptual del fingir, contemporáneo a la gramática del fingir de Wittgenstein, fue el ryleano. En El concepto de lo mental, Ryle trata de establecer una cierta gramática de la imaginación y lo imaginario, y sus relaciones con el fingimiento y el recuerdo. Si enmarcamos el trabajo de Ryle en las filas del conductismo lógico, podemos intuir las razones que le mueven a ocuparse de la imaginación. Ryle, de cualquier forma, es claro:

He mencionado el hecho terminológico de que «mental» se usa, a veces, como sinónimo de «imaginario». Las experiencias de un hipocondríaco se describen, a menudo, como «puramente mentales». Pero mucho más importante que esta rareza lingüística es el hecho de que existe una tendencia general, entre los teóricos y los hombres comunes, a adscribir cierto tipo de realidad fan- 
tasmal (other-worldly reality) a lo imaginario, considerando luego que la mente es el habitat clandestino de tales criaturas descarnadas. Las operaciones de la imaginación son, por supuesto, ejercicios de facultades mentales. Pero $[\ldots]$ pretendo mostrar que tratar de responder a la pregunta «¿Dónde existen las cosas y acontecimientos que la gente imagina?» es tratar de responder a una pregunta espuria. No existen en ninguna parte, aunque se imagine que existen, ya sea en esta habitación, o en Juan Fernández. $(1949 ; 222)$.

Dicha discusión inicia con el planteamiento que realiza Ryle en el octavo capítulo de El concepto de lo mental, en 1949. Este es sumamente rico, y dibuja un mapa conceptual bastante extenso en el que enmarca al fingimiento en el entorno de la imaginación, la fantasía, incluso el recuerdo. A pesar de las enormes virtudes del planteamiento ryleano, sabemos que el objetivo de su obra es uno solo: desmantelar lo que denomina «el dogma del fantasma dentro de la máquina». Por ello, el planteamiento que hace del fingir está viciado por el programa conductista y una tesis que a muchos posteriormente les parecería inaceptable: que el fingir se explica a partir de la dicotomía real/aparente.

Ryle piensa que, e.g., un asesinato fingido se diferencia de uno real sólo porque en el asesinato fingido no se lleva a cabo asesinato alguno. Su planteamiento con respecto a la imaginación es aún más problemático: pues para él, «imaginar $x »$ en ningún sentido propio puede constituir un caso de «ver $x »(\text { con los ojos de la mente, Ryle añade })^{17}$.

\footnotetext{
${ }^{17}$ El debate en torno a las «imágenes mentales» ha sido bastante acalorado las últimas décadas, tanto desde la psicología como desde la filosofía. Para tener un panorama general del mismo, ver Tye 2000. Para algunas críticas a la concepción conductista de las imágenes mentales, ver Kosslyn 1995, 2003 y 2006. También ya había señalado Dennett (2007) algo al respecto.
} 
Lejos de la discusión de las imágenes mentales, el caso del fingimiento es problemático en Ryle puesto que acude a la dicotomía real/aparente para dar cuenta de la diferencia entre lo fingido y lo auténtico. Algunos años después, Austin y Anscombe, en un simposio sobre el fingimiento recogido en un volumen suplementario de los Proceedings of the Aristotelian Society de 1958, con un aparato argumentativo muy sutil, tratarán de negar la implicación que realiza el conductismo para dar cuenta del fingimiento: a saber, «que el fingimiento implica no ser realmente».

Lo que tiene en mente el conductista es una tesis sumamente extravagante que recoge Austin al inicio de su contribución: el único criterio de que disponemos para diferenciar lo fingido de lo auténtico es un límite en la conducta observable. El ejemplo lo recoge Austin de Errol Bedford: la diferencia entre «sentir enojo» $\mathrm{y}$ «fingir enojo» no consiste en un estado interno que en el primer caso se presenta, mientras que en el segundo está ausente, sino en un límite con respecto a la conducta observable; así, si $A$ comienza a morder la alfombra o destruye los muebles de la habitación — piensa Bedford-parecería que no tiene sentido decir que $A$ «sólo estaba fingiendo enojo» (ver Austin 1958; 253-4).

Esta misma tesis, aunque velada, es muy similar a la que defiende Ryle. Lo que le preocupa al conductista es que el único criterio del que dispongamos para diferenciar lo fingido de lo auténtico sea la presencia o ausencia de un «estado interno». En ello no están mal encaminados. Sin embargo, tampoco es este supuesto límite en la conducta observable el criterio para distinguir lo auténtico de lo fingido.

En primer lugar, lo que habría que decirle al conductista es que si alguien que cree que finge enojo comienza a destruir los muebles de la habitación, ello tampoco nos indica que 
realmente esté enojado, sino sólo quizá que está un poco mal de la cabeza o no entiende bien qué significa «fingir enojo» ${ }^{18}$.

En esta línea, Austin y Anscombe presentan una serie de contraejemplos que parecen desacreditar la tesis conductista. Ellos se percatan de que, en una serie de casos muy bien definidos, fingir implica de hecho ser realmente. El ejemplo de Austin resulta muy esclarecedor: supongamos que $A$ finge limpiar las ventanas de la oficina de $B$ mientras toma nota de los objetos valiosos que se encuentran dentro; en dicho caso, el que $A$ finja limpiar las ventanas de la oficina de $B$ implica que, de hecho, $A$ limpie las ventanas de la oficina de $B$ (ver 1958; 259).

Las argumentaciones de Anscombe y Austin lo que intentan es mostrar la complejidad y multiplicidad de construcciones gramaticales que podemos realizar con el verbo «fingir», y con ello desacreditar la tesis conductista. Sin embargo, no muchos aceptaron las conclusiones de Austin y Anscombe (ver, e.g., Helm 1971; Barrett 1969). Otros intentaron, contra estas críticas, salvar la tesis austiniana con alguna versión modificada de sus contraejemplos (ver Binkley 1974). De cualquier forma, la discusión no llegó a ninguna conclusión satisfactoria.

Para esclarecer el debate anterior, podemos considerar la siguiente tesis: la diferencia entre lo fingido y lo auténtico radica en el propósito mismo de la práctica a la que nos estemos refiriendo; e.g., si $A$ finge limpiar las ventanas de la oficina de $B$, lo único que esto significa es que su propósito no es el mismo que el que de hecho tiene quien se gana la vida limpiando ventanas ajenas. Esto también funciona en los

\footnotetext{
${ }^{18} \mathrm{O}$ quizá, desde una perspectiva wittgensteiniana, está jugando otro juego del lenguaje: su propósito podría no ser fingir, sino, e.g., llamar la atención.
} 
ejemplos en los que fingir parece que no implica ser realmente; e.g., si un mago finge que corta en tres piezas a su asistente, su propósito no es el que tendría un supuesto asesino serial que de hecho corta en tres pedazos a sus víctimas, sino causar una ilusión visual y sorprender a su auditorio.

Por ello, y a diferencia del que finge limpiar ventanas y de hecho las limpia (pues si no las limpiara, podría despertar sospechas), si el mago en efecto cortara en tres piezas a su asistente, no cumpliría con el propósito de los trucos de magia; i.e., no causaría asombro, sino terror en su auditorio (por tanto, no fingiría que corta en tres pedazos a su asistente, sino que de hecho la estaría cortando).

Finalmente, pensemos en un caso que podría poner en cuestión la propuesta anterior: el buen actor. Este encarnaría tan bien su papel que seguiría el propósito de su correspondiente práctica fingida mientras actúa. No sólo ello, pues cuando $A$ actúa (finge) ira, de hecho siente ira, y todas sus expresiones no son fingidas, sino auténticas.

Así, parece que la gramática wittgensteiniana — su distinción entre expresiones auténticas y fingidas - resulta incapaz de diferenciar entre lo que sucede con el actor en escena y con el hombre ordinario cuando no está sobre el escenario. Reforzando lo anterior, se podría sugerir que un buen criterio para determinar si $A$ es un buen actor consiste en que sus expresiones sean auténticas. Es decir, cuando $A$ interpreta el papel de Otelo, no sólo aparenta celos, sino que los siente. Algo análogo sucede con el espectador: cuando $B$, desde su butaca, siente ira contra $A$ por asesinar a Desdémona, su ira no podría ser caracterizada como pseudo-ira, pues la vivacidad con la que la siente puede ser mucho mayor que la que lo embarga contra su vecino cuando no le deja dormir por la noche. 
En resumen, el caso del actor no es el caso del fingidor; pues, en el primer caso, los propósitos de la práctica y los estados mentales involucrados parecen ser idénticos a los del ser humano ordinario en sus prácticas cotidianas.

Contra este posible contraejemplo, podríamos argumentar que los compromisos referenciales, también determinados por las prácticas, logran establecer las diferencias entre el actor y el espectador, y el furibundo ordinario y su víctima ordinaria. Cuando $A$ (el actor que interpreta a Otelo) llora la muerte de Desdémona (la actriz que interpreta dicho papel), y $B$ (el espectador en su butaca) llora la misma muerte de Desdémona y se enfurece con, o siente pena por, Otelo, tanto los compromisos referenciales de $A$ como de $B$ no son los mismos que si dicha muerte no fuera parte de un montaje teatral: en el primer caso, ni $A$ ni $B$ van al funeral de Desdémona; en el segundo, ambos irían a su funeral y quizá guardarían luto o sufrirían el duelo ${ }^{19}$.

Aun así, tanto los buenos actores, los atentos espectadores, como los seres humanos en sus prácticas cotidianas, poseen estados mentales que no es posible diferenciar por referencia a expresiones auténticas o fingidas, o estados mentales y pseudo-estados mentales: sólo es posible establecer la diferencia a partir de los compromisos referenciales de las prácticas mismas. Wittgenstein seguramente tuvo algo así en mente cuando anotó la diferencia entre tener la representación correcta de un estado mental y tener en claro sus consecuencias:

«Sé que le ha gustado verme». — ¿Qué se sigue de esto? ¿Qué de importancia? ¡Olvídate de que tienes la representación correcta

\footnotetext{
19 Algunas de estas consideraciones las aplico de las tesis que defiende Pereda (ver 2006).
} 
de su estado mental! ¿Puedo realmente decir que la importancia de esa verdad reside en que tiene ciertas consecuencias? - Es agradable estar con alguien que se alegra de vernos, que se comporta de éste y aquel modo (si uno sabe de antes una serie de cosas sobre su conducta) (LSPP II, 49).

\section{BIBLIOGRAFÍA}

Anscombe, G. E. M. (1981). The Collected Philosophical Papers of G. E. M. Anscombe. Vol. 3. Metaphysics and the Philosophy of Mind. London: Blackwell.

Anscombe, G. E. M. (1958). «Pretending». En Anscombe (1981); 83-93.

Austin, J. L. (1961). Philosophical Papers. New York: Oxford University Press 1979.

Austin, J. L. (1958). «Pretending». En Austin (1961); 253-71.

Barrett, Cyril. (1969). «Not Exactly Pretending». Philosophy 44-170; 331-38.

Binkley, Timothy. (1974). «Real and Pretend». Philosophy and Phenomenological Research 34-4; 560-68.

Bouveresse, Jacques. (1976). Le Mythe de l'intériorité. Expérience, signification et langage privé chez Wittgenstein. Paris: Les Éditions de Minuit.

Brueckner, A. (1994). «The Structure of the Skeptical Argument». Philosophy and Phenomenological Research LIV.

Brueckner, A. (2000). «Klein on Closure and Skepticism». Philosophical Studies 98.

Cavell, Stanley. (1979). The Claim of Reason. Wittgenstein, Skepticism, Morality and Tragedy. New York: Oxford University Press. 
Currie, Gregory P. (1997). «On Being Fictional». Journal of Aesthetics and Art Criticism 55-4; 425-28.

Currie, Gregory P. (1995). «Imagination and Simulation». En Davies \& Stone (1995); 151-69.

Currie, Gregory P. (1985). «What is Fiction?». Journal of Aesthetics and Art Criticism 43; 385-92.

Darwin, Charles. (1872). The Expression of the Emotions in Man and Animals. New York: Oxford University Press 2009.

Davies, M. \& Stone, T. (eds). (1995). Mental Simulation: Evaluations and Applications Oxford: Blackwell.

Dennett, Daniel. (2007). «Re-Introducing The Concepto $f$ Mind». Electronic Journal of Analytic Philosophy 7; 12-20.

Dretske, Fred. (1970). «Epistemic Operators». Journal of Philosophy $67 ; 1007-23$

Ekman, Paul. (1996). «Why Don't We Catch Liars?». Social Research 63-3; 801-17.

Ekman, Paul. (1985). Telling Lies: Clues to Deceit in the Marketplace, Marriage and Politics. New York: W. W. Norton 1995.

Gordon, R. M. \& Barker, J. (1994). «Autism and the theory of mind' debate». En Graham \& Stephens (1994); 163-81.

Graham, G. \& Stephens, L. (eds). (1994). Philosophical Psychopathology: A Book of Readings. Cambridge: MIT Press.

Hacker, P. M. S. (1993a). Wittgenstein: Meaning and Mind, Volume 3 of an Analytical Commentary on the Philosophical Investigations, Part I - Essays. Oxford: Blackwell.

Hacker, P. M. S. (1993b). Wittgenstein: Meaning and Mind, Volume 3 of an Analytical Commentary on the Philosophical Investigations, Part II -Exegesis §§243-427. Oxford: Blackwell.

Harris, P.L. \& Kavanaugh, R.D. (1994). «Imagining the outcome of pretend transformations: Assessing the competence of normal and autistic children». Developmental Psychology 30; 847-54. 
Harris, P.L. \& Kavanaugh, R.D. (1993). «Young children's understanding of pretense». Society for Research in Child Development Monographs. (Serial No. 231).

Harris, P.L. (1995). «Imagining and pretending». En Davies \& Stone (1995).

Harris, P.L. (1994). «Understanding pretense». En Lewis \& Mitchell (1994); 235-59.

Harris, P.L. (1991). «The work of the imagination». En Whiten (1991).

Helm, Paul. (1971). «Pretending and Intending». Analysis 31$4 ; 127-32$.

Jones, C. A. (ed). (2006). Sensorium. Embodied Experience, Technolo$g y$, and Contemporary Art. Cambridge: The MIT Press.

Kosslyn, Stephen M. (2006). «Mental Image». En Jones (2006); 169-70.

Kosslyn, Stephen M. (2003). «Understanding the mind's eye... and nose». Nature Neuroscience 6-11; 1124-5.

Kosslyn, Stephen, M. (1995). «Mental Imagery». En Kuper \& Kuper (1995); 532-3.

Kripke, Saul. (1982). Wittgenstein on Rules and Private Language. An Elementary Exposition. Cambridge: Harvard University Press.

Kuper, Adam \& Kuper, Jessica (eds). (1995). The Social Science Encyclopedia. London: Routledge.

Leslie, A. (1987). «Pretense and representation: the origins of «theory of mind»». Psychological Review 94; 412-26.

Lewis, C. \& Mitchell, P. (eds). (1994). The Origins of an Understanding of Mind. Brighton: Lawrence Erlbaum Associates. Lillard, A. (1993). "Young children's conceptualization of pretense: action or mental representacional state?». Child Development 64; 372-86. 
Nichols, Shaun (ed). (2006). The Architecture of the Imagination: New Essays on Pretense, Possibility, and Fiction. Oxford: Oxford University Press.

Nozick, Robert. (1981). Philosophical Explanations. Oxford: Oxford University Press.

Pereda, Carlos. (2006). «La imaginación: ¿ornamento o creación de mundos?». Tópicos 30; 123-43.

Ryle, Gilbert. (1949). The Concept of Mind. 60th Aniversary Edition. Oxford: Routledge 2009.

Schulte, Joachim. (1987). Experience and Expression. Wittgenstein's Philosophy of Psychology. Oxford: Oxford University Press 1993.

Scruton, Roger. (1995). Modern Philosophy. An Introduction and Survey. New York: Allen Lane The Penguin Press.

Tye, Michael. (2000). The Imagery Debate. Cambridge: The MIT Press.

Valdés Villanueva, Luis M. (1996). «Estudio preliminar». En: Wittgenstein (1996).

Whiten, A. (ed). (1991). Natural Theories of Mind. Oxford: Blackwell.

Wittgenstein, Ludwig. (1996). Últimos escritos sobre Filosofía de la Psicología. Volumen II: Lo Interno y lo Externo (19491951). Madrid: Tecnos.

Wittgenstein, Ludwig. (1988a). Wittgenstein's Lectures on Philosophical Psychology. Harvester Whestsheaf. [LPP].

Wittgenstein, Ludwig. (1988b). Investigaciones filosóficas. Barcelona: UNAM-Crítica. [PU].

Wittgenstein, Ludwig. (1982). Last Writings on the Philosophy of Psychology, Volume I, Preliminary Studies for Part II of «Philosophical Investigations». Oxford: Blackwell. [LSPP I]. 


\section{RESUMEN}

En este artículo el autor presenta una sugerencia que no ha sido tratada con detenimiento en la literatura crítica: que las anotaciones que Wittgenstein elaboró sobre el fingimiento, desde las Investigaciones hasta el final de su vida, cierran en ciclo argumental iniciado con las consideraciones sobre el seguimiento de reglas. Éstas pretenden atacar una última posibilidad escéptica que Stanley Cavell —en su célebre Reivindicaciones de la razón- no consideró relevante: el sentido de secreto del concepto de privacidad. En otras palabras, puede ser que la conducta del otro sea fingida: parece que toda la evidencia de la que dispongo de los estados mentales del otro - piensa el escéptico- es compatible tanto con una experiencia real de un estado mental (e.g., dolor) como con una vivencia fingida (e.g., dolor fingido).

Palabras clave: Wittgenstein; fingir; imaginación; otras mentes.

\section{ABSTRACT}

This paper presents a suggestion that has not been treated extensively in the critic literature: that the notes that Wittgenstein elaborated on pretense closed the argument started with the rule following considerations. They aim is to strike a last skeptical chance - which Stanley Cavell in his famous The Claim of Reason not considered relevant-: the sense of secret inside the concept of privacy. In other words, it may be that the behavior of the other is a fake: it seems that all the evidence that I have of the other's mental states, thinks the skeptic, supports both real experience of a mental state (e.g., pain), and experience as a feigned (e.g., feigned pain). 
Keywords: Wittgenstein; pretense; imagination; other minds. 